\title{
THE ENGLISH QUESTION: RISING OR FALLING INTONATION
}

\author{
Yao Shen \\ University of Michigan
}

One of the problems which constantly faces the teachers of English as a foreign language as well as their instructor in a teacher-training program is the intonation pattern of the English question. Does the English question have a rising intonation or does it have a falling one? Their instructor's answer usually is, "Both, and they are different in meaning." The teachers in general are unanimous in accepting the rising intonation. But on the falling one, the reaction is different. That most of them accept their instructor's answer is not because of their intellectual conviction but rather because they are too polite to argue. However, the information that the English language has a falling intonation remains in their minds with a deep unrest. Let us assume that they accept the fact that there are two intonations. The next question is which intonation they should teach. If the falling intonation is suggested, the unvoiced disturbance is often louder than the voiced disagreement.

In this short article, we shall first summarize the main question patterns in English as described in Charles C. Fries's Structure of English. Next we will investigate what some linguists have said about the distribution of the rising and falling intonations in questions. Finally, we will discuss what the teachers can profitably do and why.

In describing the different patterns of the English question, Fries divides them into the following groups:
1. Class $2 \longleftrightarrow$ Class 1
2
1
Were the teachers there ${ }^{1}$

${ }^{1}$ Charles C. Fries, The Structure of English, (New York, 1952), p. 148. See also pp. 158-164 for the five types of Class $2 \longleftrightarrow$ Class 1 that are not questions. 


\section{LANGUAGE LEARNING}

2. Function Word Group B or Group $G$ with the following patterns:
a. Group Class Class B(a)
2
b. Group Class Class
G $\quad 1 \quad 2$
B(a) $\quad 1 \quad 2$
Would Tuesday be possible 2
G $\quad 1 \quad 2$
Does he have to go tonight 3

3. Function Word Group I with the following patterns: I
2
1
a. Group Class Class
I 2
1
When was the concert good 4
b. Group Group Class Class I G 12 I
G 1 2 When did the student call 5
c. Group
I (as Class 1)
2
Class
I 2
Who came 6

4. Function Word Group I alone as questions: ${ }^{7}$

a. With a rising intonation. "The rising pitch sequence occurs in those situations in which the question seeks a repetition of a portion of the utterance immediately preceding."

b. With a falling intonation. "The falling pitch sequence occurs in those situations in which the question seeks additional information."

5. The rising intonation that constitutes the echo question: ${ }^{8}$

a. "A repetition of a whole or a part of a statement is uttered by another speaker, usually immediately after the statement has been made.

This repetition contains the same word-order pattern as the statement of which it is a partial echo, but,

2Ibid., p. 150 .

3Ibid., p. 151.

4Ibid., p. 98.

6Ibid., p. 99; pp. 151-152.

5Ibid., p. 99 .

7 Ibid. , pp. 154-155.

8Tbid., pp. 157-158. 


\section{THE ENGLISH QUESTION}

by means of a contrast of the intonation or pitch sequence at the end, it becomes a question."

b. "Sometimes there is no utterance of which the sentence with a rising intonation is an echo."

Questions in English have both the rising and the falling intonation patterns. Bloomfield says:

Within the domain of final-pitch we can distinguish several phonemic differences. It's ten o'clock, as a statement, differs from it's ten o'clock? as a question; the latter ends with a rise, instead of a fall. Among questions, there is a difference of pitch-scheme between a yes-or-no question, such as It's ten o'clock? or Did you see the show? and a supplement-question, which is to be answered by some special word or phrase, as What time is it? or Who saw the show? with a lesser rise at the end. In transcription we may indicate the latter type by placing the question-mark upside down [द]. ${ }^{9}$

In English, supplement-questions are distinguished not only by their special pitch-scheme [i], but also by a selective taxeme: the form used as a supplementquestion either consists of a special type of word or phrase, which we may call an interrogative substitute, or else contains such a word or phrase; Who? With whom? Who ran away? With whom was he talking?10

In his description of the structural patterns of the English question Fries mentions the use of the rising intonations in some questions. 11 He also shows how a falling intonation in a question contrasts with a falling intonation in the middle of a statement, 12 how the falling intonation contrasts with the rising intonation in the same question, 13 how the falling intonation in questions contrasts with the falling intonation in utterances that are not questions, 14 and how the falling intonation is used for both the statement and the question. 15

${ }^{9}$ Leonard Bloomfield, Language, (New York, 1933), pp. 114-115.

10rbid., p. 171. Bloomfield probably heard a slight trailing or the "lesser rise" after the falling from 2 to 4 . But immediately preceding the slight trailing there is the 2-4 falling.

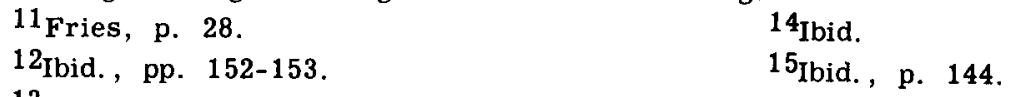

${ }^{13}$ Ibid. , p. 163. 


\section{LANGUAGE LEARNING}

Pike describes the intonation patterns in questions in great detail. We shall limit ourselves in this discussion to the 3-2 rising pattern and the 2-4 falling pattern. According to Pike, questions that begin with interrogative pronouns have a rising or a falling intonation. 16 But most of them have a falling intonation. 17 When such questions have a rising intonation, they either elicit a repetition of the previous utterance or indicate politeness. 18 Questions without interrogative pronouns more frequently have a rising intonation than a falling one. 19 Questions which "contain inverse word order" have both the rising and the falling intonations. 20 "Phrases with normal word order" become questions when a rising intonation is used. 21

From the descriptions of these three linguists, we may conclude: 1. Statements become questions when a rising intonation is used. 2. Questions have both the rising and the falling intonations.

Teachers of English even without the detailed information on the juxtaposition of the question patterns and intonation patterns must make an important and necessary decision when they teach students of the elementary level. At the elementary level, it is not possible to teach all intonation patterns distributed among all the question patterns. The teachers must choose between these alternatives: Should they select one intonation pattern and spend time helping students to acquire more question patterns; or, should they teach all the possible intonation patterns used with the same question pattern before they go on to another? Most teachers would probably prefer the former. If so, the next decision is: Should the rising intonation or the falling one be taught?

The decision in favor of the falling intonation is a fairly sound one. There are several reasons. First, in many languages, such as Spanish and Chinese, a rising intonation automatically indicates a question. The teacher need not teach the students that intonation. It is within their productive ability. To teach them the rising intonation is no additional acquisition. Second, statements become questions when produced with a rising intonation. The teacher perhaps would not want the students to form questions with statements using a rising

16 Kenneth L. Pike, The Intonation of American English, (Ann Arbor, 1945), p. 46.

17 Ibid. , p. 168.

18 Ibid., pp. $46-47$.

19 Ibid., p. 169.

20Ibid., pp. 52-54.

21 Ibid., p. 53. 


\section{THE ENGLISH QUESTION}

intonation too frequently. Third, a continuous series of questions with a rising intonation tends to make the conversation sound insincere or over-polite. One does not want to impress the native speaker with a type of intonation that expresses a doubtful attitude or an over-courteous manner. If to be able to speak a language is to help to bridge the gap between two persons or two peoples, one would not want to master a continuous series of rising intonations. Fourth, there are questions in English with the same falling intonation as that of a statement. Thus the intonation does not tell the students whether the utterance is a statement or a question. It is this very reason why the falling intonation should be used. In English, questions with the falling intonation have other ways of signaling the question. These signals are found at the beginning of the utterance. If the falling intonation is used, students would have no other way of distinguishing a statement from a question save to compel themselves to look for the signal at the beginning. Thus the difference is not

Question

3-2

but

$$
\begin{aligned}
& \text { Question }(2-4) \\
& \text { Were the teachers ... } \\
& \text { Would Tuesday be ... } \\
& \text { Does he have....... }
\end{aligned}
$$

Statement

2-4

\section{Statement $(2-4)$}

The teachers were... Tuesday would be.... Yes, he does

Even in a language such as Lebanese Arabic which normally uses the 2-3 falling intonation for the question and the 2-4 falling intonation for the statement regardless of word order, 22 the Lebanese Arabic speaker learning English still needs to focus his attention on the question signal at the beginning of the utterance.

Looking for the question signal at the beginning of the utterance has another advantage in the accumulation of language control. One of the ways to help students to recognize and produce English is to focus their attention on the signal. Many instances like the following can be found when students say, "Yes, I do" or "Yes, I am" when the question is "Can you go to the concert?" If the students are compelled to

${ }^{22}$ This information is given by Dr. Ernest N. McCarus. 


\section{LANGUAGE LEARNING}

notice the signal at the beginning, they will be reminded to respond with "Yes, I can." For the form of the signal is already given them. Focussing their attention on the beginning of the question is especially important with questions that have question words such as what, where, which, when, why, how, who. Students must cultivate the habit of noticing at the same time the lexical difference among utterances such as the following:

\begin{tabular}{|c|c|}
\hline $\begin{array}{l}\text { What is it } \\
\text { When is it }\end{array}$ & $\begin{array}{l}\text { Where is it } \\
\text { Why is it }\end{array}$ \\
\hline
\end{tabular}

If the students are trained to look for the question signals which in English generally come at the beginning of the utterance, then learning English will be a matter of much less confusion.

Those who teach English as a foreign language would all admit that not to teach the juxtaposition of the intonation patterns with the question patterns is to deny the students the entire scope of the English question. Not to be able to control either all the intonation patterns or all the question patterns constitutes a lack in the total mastery of the English question. For only when a person has mastered all the patterns in a language has he acquired what Fries calls "freedom" in the language. But with the choice given here, it is more practical to teach the 2-4 intonation with a wider range of question patterns than to teach all intonation patterns with fewer questions. Without all the possible intonation patterns, students will not be able to express as much as they might. But without all the question patterns students will not be able to communicate.

Teaching the falling intonation does not mean that the teacher is ignoring the rising intonation. When visiting classes, one easily notices that the teacher often produces the rising intonation himself in asking students questions. For the rising intonation is the necessary one when he wants the students to repeat or he is expressing a courteous attitude or both. Thus students hear it frequently. In an advanced class, the rising intonation may be taught so that the students will master the different meanings of the same question pattern when the only difference is the sentence intonation. For example: 


\section{THE ENGLISH QUESTION}

1. Q. Do you like cake or pie (2-4)

A. a. Cake.

b. Pie.

c. Both.

d. Neither.

Q. Do you like cake or pie (3-2)

A. a. Yes, I do. (I like cake or pie.)

b. No, I don't. (I don't like cake or pie.)

2. Q. Did your aunt have a boy or a girl (2-4)

A. a. A boy.

b. A girl.

c. Twins.

Q. Did your aunt have a boy or a girl (3-2)

A. a. Yes, she had several (children).

b. No, she didn't have any (children).

Intonation differences can be taught to the advantage of an advanced class. But for the elementary class when the students still have to master the different question patterns, the falling intonation is the preferred one. 